\title{
La poética de la imagen en la poesía de Cesare Pavese
}

\author{
ROSARIO SCRIMIERI \\ Universidad Complutense de Madrid \\ roscrimieri@filol.ucm.es
}

\section{Resumen}

Se trata de las reflexiones que Cesare Pavese realiza acerca de la poética de la imagen a propósito de su libro Lavorare stanca (1936) en Il mestiere di poeta (1934), así como en A proposito di certe poesie ancora non scritte (1940), poniéndose en relación sus consideraciones con los presupuestos de la tradición poética del simbolismo. Igualmente se examina la poética de la imagen en La terra e la morte (1945), última obra publicada en vida de Pavese, en relación con los conceptos de imagen arquetípica y símbolo.

Palabras clave: Poética, imagen, correspondencias, relato, símbolo.

The poetics of image in Cesare Pavese's poetry

\begin{abstract}
The essay deals about the reflections of Cesare Pavese over the poetic of image ruling his book Lavorare stanca (1936), reflections inclosed in Il mestiere di poeta (1934), and also in A proposito di certe poesie ancora non scritte (1940); it brings to connexion Pavese's reflections with the traditional principles of the poetry of symbolism, and it examines as well the poetic of image in La terra e la morte (1945) -the last poetry book published still alive Pavese- in connection wth the concepts of archetypical image and symbol.
\end{abstract}

Key words: Poetics, image, correspondences, narration, symbol.

Scrimieri, Rosario. 2011. La poética de la imagen en la poesía de Cesare Pavese. Cuadernos de Filología Italiana, $\mathrm{n}^{\mathrm{o}}$ extraordinario: págs. 339-354.

Este trabajo trata sobre las reflexiones que Cesare Pavese realiza acerca de la imagen a propósito de su libro Lavorare stanca (1936) en Il mestiere di poeta, escrito de 1934 publicado en la segunda edición de Lavorare stanca de 1943, donde 
añade una serie de nuevas poesías y un apéndice formado por el citado escrito y otro de 1940, titulado A proposito di certe poesie ancora non scritte. En concreto, me voy a detener en el modo en que Pavese dice que elabora la imagen, poniendo en relación sus consideraciones con la tradición poética del simbolismo. Como observa Curi, «in ogni settore della poesia novecentesca scorre il sangue della poesia simbolista» (Curi 1977: 14), pero hay que añadir, como también lo hace este crítico, que este flujo de sangre simbolista discurre, en la poesía italiana del Novecento, por cuerpos muy diferentes entre sí, produciéndose por ello diferentes manifestaciones de poética y de poesía. Igualmente examinaré brevemente el poemetto La terra e la morte, última obra publicada en vida de Pavese, en 1945, relacionándolo igualmente con el tratamiento de la imagen y con la tradición poética del simbolismo.

En la primera parte de $\mathrm{Il}$ mestiere di poeta Pavese reflexiona sobre los rasgos esenciales que configuran la poética de Lavorare stanca: unos rasgos que considera en abierta polémica con las poéticas imperantes en el momento en que escribe, dominado por el hermetismo, rasgos que, como él mismo dice, se han fraguado al contacto con la literatura norteamericana, en oposición a la tradición de la modernidad europea ${ }^{1}$. En este sentido y para abordar de un modo sintético cuanto expone Pavese en sus reflexiones, podríamos decir que dos son los fenómenos de poética que, a lo largo del Novecento, determinan la destrucción o la muerte de la poesía lírica tal como venía siendo cultivada por la gran tradición del simbolismo: por un lado, la contaminación, el hibridismo con otros géneros, en especial su «romanzizzazione», en el sentido no sólo de su contaminación con la prosa narrativa sino también en el de la libertad que la anima a partir del ejemplo de la novela, con las consecuencias que ello tiene en la transformación del lenguaje aúlico tradicional y en la organización de los versos. Y, por otro, la destrucción del sujeto lírico, la muerte del yo poético. De ambos aspectos habla Pavese en su escrito. Nosotros nos detendremos aquí en el tema que nos ocupa, las reflexiones del autor en torno a la imagen, su poética de la imagen en relación con la poética de las correspondencias y de la epifanía, propias del simbolismo, algo que nos llevará en muchos momentos a tocar los dos fenómenos de poética apenas citados y que de modo general configuran el devenir, la muerte-transformación de la lírica italiana en el Novecento. Pavese concentra estas reflexiones en torno a la imagen en la segunda parte de Il mestiere di

\footnotetext{
1 Son de gran interés las consideraciones que hace Alfonso Berardinelli sobre las relaciones de Italia, y en general de Europa, con Norteamérica cuando trata sobre la postmodernidad, reflexiones que se pueden también aplicar a la atracción de Pavese por la novela de los EE.UU.: « [...] le vicende postmoderne [...] alludono a una svolta fondamentale nel modo di considerare e di ereditare la Modernità, una svolta avvenuta prima di quanto in genere si pensi. Il Postmoderno inizia con gli anni Quaranta, soprattutto dopo la Seconda guerra mondiale, quando la centralità europea è ormai tramontata e il Novecento come «secolo americano» esce dallo stato di latenza per manifestarsi nelle forme più evidenti in tutti i campi: politica, economia, stile di vita, cultura di massa e cultura di élite. Da allora Europa «si aliena», guarda sempre più a se stessa con gli occhi dell'America, dal punto di vista degli Stati Uniti, considerati il punto culminante e più avanzato dello sviluppo occidentale. Contrariamente a quello che tanto spesso si ripete, la sinistra europea non ha peccato affatto di antiamericanismo, quanto piuttosto del contrario: il mito dell'America (più forte di quello della Russia) abita stabilmente le viscere della cultura europea, soprattutto della cultura di sinistra, fin dagli anni Trenta» (Berardinelli 2008: 35-36).
} 
poeta, cuando se detiene a considerar cómo compuso el poema Paesaggio, el tercero de Lavorare stanca.

Es necesario, sin embargo, recordar ciertos puntos de la primera parte de su escrito, relacionados con la búsqueda de una poética de la objetividad: «c'era da raggiungere l'evidenza fantastica fuori da tutti gli altri atteggiamenti espressivi viziati, a me pareva, di retorica; c'era da provare a me stesso che una sobria energia di concezione portava con sé l'espressione aderente, immediata, essenziale» (Pavese 1998: 108) (subrayados míos).

Y respecto de la imagen, retóricamente entendida, observa: «non ne volevo nelle mie poesie e non ce ne mettevo (se non per sbaglio). Era per salvare l'adorata immediatezza e [...] sfuggire il facile e slabbrato lirismo degli immaginifici (esageravo)» (Pavese 1998: 108) (subrayado mío).

No se puede evitar el percibir en estas declaraciones de intenciones ciertas resonancias de lo que dice Montale en Intenzioni (Intervista Immaginaria) (1946), en torno a la composición de Ossi di seppia (1925), a pesar de las grandes diferencias que existen entre estos dos poetas: «Volevo che la mia parola fosse più aderente di quella degli altri poeti che avevo conosciuto» (Montale 1976: 565). Y respecto del rechazo de la retórica, Montale dice: «all'eloquenza della nostra vecchia lingua aulica volevo torcere il collo, magari a rischio di una controeloquenza», entendiéndose aquí elocuencia como término equivalente al de retórica, aunque Montale parece referirse preferentemente al plano de la forma de la expresión, y Pavese al plano semántico de la imagen, al de la forma del contenido. Hay un paralelismo, a mi modo de ver, en esa intención de adherencia, de inmediatez y de prosecución de lo esencial en ambos poetas aun siendo evidentes también las diferencias que existen entre sus realizaciones poéticas concretas. Pero precisamente el acercamiento entre Montale y Pavese nos puede ayudar, a mi modo de ver, a comprender lo que este último realiza en Lavorare stanca en relación con la elaboración de la imagen, en concreto cuando habla del poema Paesaggio; nos puede ayudar a descubrir cómo circula la sangre simbolista en el cuerpo de la poesía de Pavese.

De ese poema Pavese comienza diciendo: «misi insieme un Paesaggio di alta e bassa collina, contrapposte e movimentate, e, centro animatore de la scena, un eremita», enumerando después los rasgos de este último: «alto e basso, superiormente burlone», y «del colore delle felci bruciate» (Pavese 1998: 110). Una vez más vienen a la memoria, respecto de la preeminencia del paisaje en este poema, las palabras de Montale a propósito de una de las primeras y también más famosas poesías de Ossi di seppia: Meriggiare pallido e assorto ${ }^{2}$, compuesto su primer fragmento, dice Montale, «tout entier à sa proie attaché /.../ La preda era, s'intende il paessaggio» (Montale 1976: 563), y poesía dotada, como Paesaggio, de dos partes: la primera, formada por las tres primeras estrofas, totalmente «à leur proie attachées», es

\footnotetext{
2 «Meriggiare pallido e assorto / presso un rovente muro d'orto / ascoltare tra i pruni e gli sterpi / schiocchi di merli, frusci di serpi. / Nelle crepe del suolo o su la veccia / spiar le file di rosse formiche / ch'ora si rompono ed ora s'intrecciano / a sommo di minuscole biche. / Osservare tra frondi il palpitare / lontano di scaglie di mare / mentre si levano tremuli scricchi / di cicale dai calvi picchi. / E andando nel sole che abbaglia / sentire con triste meraviglia / com'è tutta la vita e il suo travaglio / in questo seguitare una muraglia / che ha in cima cocci aguzzi di bottiglia» (Montale 1995: 30).
} 
decir, totalmente adheridas al paisaje y dedicadas a la difusión de las imágenes, y la segunda, de índole diferente, resolutoria del poema, hecha de concentración gracias a la presencia del símbolo. «Sapevo anche allora-dice Montale- distinguere tra descrizione e poesia, ma ero consapevole che la poesia non può macinare a vuoto e che non può aversi concentrazione se non dopo diffusione» (Montale 1976: 563). Lo que se advierte en la poesía de Montale es que la enumeración de las imágenes se enhebra en el hilo de una subjetividad, de una ensoñación íntima, y ello, aunque en el poema montaliano no aparezca una forma verbal conjugada en primera persona; en este aspecto, las formas del infinitivo no representan tanto la anulación del yo, del sujeto experimentador, cuanto su ampliación, un modo de universalización de la experiencia que se hace compatible con los otros a través del uso del infinitivo. La poesía de Montale posee, pues, una carga de opacidad subjetiva: la palidez y el ensimismamiento del sujeto, su sentimiento de «triste meraviglia», y la representación de una serie de experiencias sensoriales que presuponen y son prueba de la presencia de un yo $^{3}$ aunque este se halle gramaticalmente ausente. Así, se puede decir que el poema, en su primera parte, pone la subjetividad en el centro del mundo, en el centro de las imágenes representadas; y en la última estrofa, trámite la analogía, gracias a la correspondencia dentro-fuera, el espacio exterior se transforma en la proyección del espacio interior, se convierte en correlativo objetivo de la subjetividad. En el poema de Montale una serie de rasgos pueden considerarse característicos de la tradición de la poesía simbolista: el culto a la percepción sensorial, a la inmersión del sujeto en las sensaciones (en el caso de Montale de percepciones auditivas y visivas, en detrimento del gusto, olfato y tacto, los llamados sentidos inferiores que privilegió la sensorialidad simbolista), y cómo una subjetividad transida de sensaciones, que se difunde y expande por todo el poema, es la que construye a este último.

Si consideramos ahora el poema Paesaggio $^{4}$ en relación con los problemas que acabamos de tratar, en primer lugar, respecto de la cuestión de la presencia del yo,

3 Se podrían añadir a estas consideraciones las reflexiones que, de modo general, Mazzoni dedica a la lírica moderna: «la lirica moderna rimanda un'immagine del mondo personalistica e monadica: il centro della rappresentazione non è l'agire interumano messo in scena, o il racconto delle storie e dei loro intrecci, ma il modo in cui un io isolato riferisce alcune esperienze per lo più individuali, irrelate, intense e istantanee. Nessun altro genere, neppure l'autobiografia, è così egocentrico, nel contenuto come nella forma» (Mazzoni 2005: 204).

4 «Non è più coltivata quassù la collina. Ci sono le felci / e la roccia scoperta e la sterilità. / Qui il lavoro non serve più a niente. La vetta è bruciata / e la sola freschezza è il respiro. La grande fatica / è salire quassù: l'eremita ci venne una volta / e da allora è restato, a rifarsi le forze. / L'eremita si veste di pelli di capra / e ha un sentore muschioso di bestia e di pipa, / che ha impregnato la terra, i cespugli e la grotta. / Quando fuma la pipa in disparte nel sole, / se lo perdo non so rintracciarlo, perché è del colore / delle felci bruciate. $\mathrm{Ci}$ salgono visitatori / che si accasciano sopra una pietra, sudati e affannati, / e lo trovano steso, con gli occhi nel cielo, / che respira profondo. Un lavoro l'ha fatto: / sopra il volto annerito ha lasciato infoltirsi la barba, / pochi peli rossicci. E depone gli sterchi / su uno spiazzo scoperto, a seccarsi nel sole. /

Coste e valli di questa collina son verdi e profonde. / Tra le vigne i sentieri conducono su folli gruppi / di ragazze, vestite a colori violenti, / a far festa alla capra e gridare di là alla pianura. / Qualche volta compaiono file di ceste di frutta, / ma non salgono in cima: i villani le portano a casa / sulla schiena, contorti, e riaffondono in mezzo alle foglie. / Hanno troppo da fare e non vanno a veder l'eremita / i villani, ma scendono, salgono e zappano forte. / Quando han sete, tracannano vino: piantandosi in bocca / la bottiglia, sollevano gli occhi alla vetta bruciata. / La mattina sul fresco son già di ritorno spossati / dal lavoro dell'alba e, se passa un pezzente, / tutta l'acqua che i pozzi riversano in mezzo ai raccolti / è per lui che la beva. Sogghignano ai gruppi di donne / o domandano quando, vestite di pelle di capra, / siederanno su tante colline a annerirsi nel sole» (Pavese 1998: 31). 
Pavese dice que el «centro animatore della scena» es un ermitaño. Solo en el verso 11 aparece la primera persona: «se lo perdo non so rintracciarlo»; es decir, aquí se hace textualmente presente el sujeto de la percepción, de quien está observando y describiendo el paisaje: la árida colina y su habitante. A diferencia de Montale que, a propósito de Meriggiare pallido e assorto, dice que sabe distinguir entre descripción y poesía, y que es consciente de que la poesia «non può macinare a vuoto», en el sentido de que debe agotar una situación psicológica, parece que Pavese aquí no sabe distinguir entre descripción y poesía, parece que «macina a vuoto» en el sentido de que ninguna opacidad subjetiva empaña la mirada del que observa, de que ninguna sensación o sentimiento se interfieren en esa mirada (nada del pálido ensimismamiento, de la «triste meraviglia» de la mirada del texto montaliano), y en el sentido de que su poema carece de la concentración resolutoria de una imagen simbólica final. Aunque sí que podríamos encontrar una huella de la presencia de ese sujeto -no la de su intimidad psíquica sino la de su fisicidad corporal- en la breve alusión a la respiración: «e la sola freschezza è il respiro» (v. 4), y al esfuerzo corporal: «la grande fatica / è salire quassù» (vv. 4-5), donde emerge la presencia del cuerpo y con él la sensación de cansancio, tema que atraviesa la obra poética de Pavese. El propio Pavese, sin embargo, detecta en la descripción que su poema hace del ermitaño algo que se ha escapado a su resuelta voluntad de erradicar al yo de su poesía, voluntad que de modo rotundo expresa en la parte final de Il mestiere di poeta; detecta la presencia de un yo, que con gran penetración Pavese liga a la poética de la imagen y a la visión de las correspondencias entre las imágenes:

Mi impensieriva /.../ la sfacciata preminenza data all'io (che fin dal tempo de $I$ mari del Sud era stato mio polemico vanto ridurre a mero personaggio e talvolta abolire), non tanto intendendolo argomento oggettivo, ché era ormai timore puerile, quanto perché alla preminenza dell'io mi pareva di vedere accompagnarsi un più sregolato gioco di rapporti fantastici (Pavese 1998: 112).

Lo que se le ha escapado a Pavese «a dispetto dei convincimenti anti-immaginifici», por tanto, es una imagen, una analogía que la mirada supuestamente objetiva del observador, establece entre el ermitaño y «il colore delle felci bruciate», correspondencia por donde el poeta es consciente de que puede filtrarse, se filtra de hecho, la subjetividad, la presencia del yo. Un poco más adelante, sin embargo, Pavese explica esa correspondencia en otro sentido, no como huella sensorial subjetiva, ni como mera imagen retórica sino en función de otro tipo de manifestación poética que él denomina «rapporto fantastico»: «che l'eremita apparisse colore delle felci bruciate non voleva dire che io istituissi un parallelo tra eremita e felci per rendere più evidente la figura dell'eremita o quella delle felci. Voleva dire che io scoprivo un rapporto fantastico tra eremita e felci, tra eremita e paesaggio» (Pavese 1998: 111). Se trata, pues, de una imagen cuya importancia no descansa en el significado retórico inherente a la figura de la comparación sino en aquel significado -dice Pavese- «ultimamente intravveduto, di parti costitutive di una totalitaria realtà fantastica, il cui senso consistesse nel loro rapporto» (Pavese 1998: 111). 
Es pues la noción de «rapporto fantastico» el núcleo de la poética de la imagen en la poesía de Lavorare stanca, una noción sobre la que nos debemos preguntar si puede considerarse equivalente o hasta qué punto es equivalente al principio de las correspondencias de la poética simbolista. Baudelaire ${ }^{5}$ consagró este principio como uno de los componentes de su poética, considerando que la capacidad primordial del verdadero poeta es la de ser un descifrador, un descubridor de las correspondencias existentes entre las cosas aparentemente más alejadas entre sí, poniendo el poeta en evidencia de este modo el fondo inagotable y unificado de toda la realidad. Hasta tal punto resulta consagrado este principio en la modernidad que símbolo y poesía quedan en ella equiparados. ¿Está presente en Il mestiere di poeta y en el poema Paesaggio tal tipo de visión? Pavese, después de decir que ha descubierto un «rapporto fantastico» entre el ermitaño y los helechos, entre el ermitaño y el paisaje, continúa diciendo que ese tipo de relación podría continuar: «(si può continuare: tra eremita e ragazze, tra visitatori e villani, tra ragazze e vegetazione, tra eremita e capra, tra eremita e sterchi, tra alto e basso)» (p. 111). Se podría contestar, por tanto, que, en principio, sí que estaríamos ante la enunciación del principio de las correspondencias, de las que, sin embargo, ha desaparecido, en primer lugar, la mirada transida de la opacidad subjetiva (la sensorialidad, el sentimiento, las intuiciones, los pensamientos del yo poético), es decir, estaríamos ante unas correspondencias de imágenes, como diría Montale, «macinate a vuoto». Y, por otra parte, estaríamos ante una poética de las correspondencias que ha desechado el modo simbólico propio de la poética simbolista, el mecanismo sintetizador de la metáfora basado en la manipulación del nivel semántico del lenguaje y en la continua transformación de los significantes y el valor de los sememas. En Paesaggio los pares de contrarios que aparecerían reunidos en la unidad del símbolo, aparecen desintegrados en dos tiempos textuales, aparecen discursivizados. Pavese lo explica así: «capitò che un giorno, volendo fare una poesia su un eremita, da me immaginato, dove si rappresentassero i motivi e i modi della conversione, non riuscivo a cavarmela e, a forza d' interminabili cincischiature ritorni pentimenti ghigni e ansietà, misi invece insieme un Paesaggio di alta e bassa collina, contrapposte e movimentate» (Pavese 1998: 110). Pavese pues deshace la instantánea simultaneidad de las imágenes propia de la metáfora, la simultánea tensión de opuestos que constituye la complejidad del símbolo, tensión de contradicciones que, según el modo simbólico, convergería en una subjetividad, aquí proyectada en la del «eremita», uno y a la vez dividido. Pavese deshace las metáforas, los símiles y presenta los términos de la analogía en dos tiem-

\footnotetext{
5 Baudelaire, en un fragmento de L'art romantique, siguiendo las enseñanzas del místico sueco Swedenborg (1688-1772), considera que: «[...] tutto, forma, movimento, numero, colore, profumo, nello spirituale come nel naturale, è significativo, reciproco, converso, corrispondente [...] tutto è geroglifico e noi sappiamo che i simboli sono oscuri soltanto in modo relativo, cioè secondo la purezza, la buona volontà e la chiaroveggenza native delle anime. Ora che cosa è un poeta (prendo la parola nella sua accezione più ampia) se non un traduttore, un descifratore? Nei poeti eccellenti non c'è metafora, similitudine o epiteto che non sia adattato con matematica esattezza alla circostanza attuale, perché quelle similitudini, quelle metafore sono attinte all'inesauribile profondità dell'universale analogia e non possono essere attinte altrove») (en Luzi 1976: 106-107).
} 
pos distintos, discursiviza esos términos para así sacarlos del ámbito de una conciencia. Es como si Baudelaire, por ejemplo, en su famoso poema La Chevelure presentara, por un lado, la descripción objetiva del cabello de su amada y después, en un segundo tiempo, yuxtapuesta, la descripción de los paisajes lejanos y exóticos, obviando los semas de intersección de carácter subjetivo-sensorial, los que permiten realizar las correspondencias entre uno y otro ámbito, haciendo desaparecer con ello el componente emocional y extático de la composición.

No sabemos cómo habría resultado el poema de Pavese realizado según el modo simbólico, utilizando correspondencias simultáneas, es decir, metáforas que contuvieran de modo sintetizado las correspondencias que en Paesaggio aparecen explícitas y discursivizadas, y que el propio Pavese reconoce y enumera cuando habla de la potencialidad de los «rapporti fantastici» que se pueden descubrir en su poema: como, por ejemplo, en el espacio elevado del paisaje, que es también el espacio elevado del texto, las correspondencias que se dan «tra eremita e felci; tra eremita e capra, o tra eremita e sterchi»; o las que se producen entre el espacio alto y bajo, «tra eremita e ragazze, tra visitatori e villani»; o aquellas que se establecen en el espacio bajo del paisaje, en las laderas y valles de las colinas, «tra ragazze e vegetazione». Y se podría continuar con otras que Pavese no menciona, como aquella «tra eremita e cielo», inherente al verso «e lo trovano steso, con gli occhi nel cielo» (v. 14), o aquella «tra ragazze e capra»: «[...] folli gruppi / di ragazze, vestite a colori violenti, / a far festa alla capra» (vv. 21-23), que connota la explicitada por Pavese «tra eremita e ragazze» y que, de un modo burlón o malicioso, cierra el poema: «Sogghignano ai gruppi di donne / o domandano quando, vestite di pelle di capra, / siederanno su tante colline a annerirsi nel sole». En todas estas correspondencias subyacen semas de intersección que pertenecerían a la subjetividad del sujeto-eremita, desgarrándolo en pares de opuestos: trabajo $v s$. ociosidad, fertilidad $v s$. esterilidad, sexualidad dionisiaca $v s$. castidad, compañía vs. soledad, todas ellas comprendidas en la gran oposición espacial bajo vs. alto. Habría sido un poema densísimo, cargado de opacidad subjetiva por la que se habría filtrado la opacidad subjetiva del propio yo poético, mientras que de lo que se trataba en la nueva escritura de Pavese era apartarse por todos los medios de «un lirismo [...] di sfogo e di scavo (povero scavo che sovente dava nel gratuito e sfogo vizioso che sempre fini nell'urlo patologico)» (Pavese 1998: 107). Pavese confiesa, sin embargo, que «non riusciva a cavarsela» en la representación de ese proceso de conversión, que necesariamente habría de conllevar íntimos y contradictorios movimientos de la conciencia, y finalmente opta por salirse de la subjetividad, que equivale a abandonar la poética del yo lírico, en favor de la tercera persona y de la mirada y de la descripción objetivas.

Pavese utiliza, por tanto, las correspondencias pero en vez de usarlas según el modo simbólico, remitentes al fondo profundo y unificado de la subjetividad, a la «tenebrosa y profunda unidad / vasta como la noche y como la claridad» baudelairiana, sintetizadas en la metáfora o desplegadas en el símil (recordar como paradigma de este último procedimiento el poema Le stirpi canore de D'Annunzio), Pavese disocia los términos de la posible analogía, de la posible correspondencia, convirtiéndola en un rapporto fantastico, en germen de invenciones fantásticas: «volevo dire che io scoprivo un rapporto fantastico tra eremita e felci, tra eremita e pae- 
saggio /... / che era esso argomento del racconto» (Pavese 1998: 111). Lo que revelan las imágenes así disociadas es una potencialidad objetiva de relaciones, transformables para Pavese en múltiples posibilidades de «racconto»; una potencialidad que es necesario explicitar descubriendo el sema oculto de la intersección que liga los posibles términos de relación entre las imágenes del nivel alto y del nivel bajo del paisaje, en oposición a la «nebulosa de contenido» a la que apunta el referente del modo simbólico, un referente en último término desconocido e inaferrable, y cuya prosecución última se materializaría en la poética de la epifanía, de la que el joven Montale también era consciente cuando habla de la elaboración de Ossi di seppia: «Un velo sottile, un filo appena mi separava dal quid definitivo. L'espressione assoluta sarebbe stata la rottura di quel velo, di quel filo: una esplosione, la fine dell'inganno del mondo come rappresentazione. Ma questo era un limite irraggiungibile» (Montale 1976: 565).

Estamos aquí ante la búsqueda de la revelación del secreto último de la realidad, de ese fondo unificado al que el símbolo solo puede referirse como una "nebulosa de contenido", donde yacen unificadas todas las posibilidades y los opuestos de la realidad, algo que Montale sabe que es «irraggiungibile», y que provoca, por ejemplo, el tenso registro de interpelación al mar que recorre la serie Mediterraneo. Por eso Montale concluye, tras las palabras anteriormente citadas, que su voluntad de adherencia, al final, «restava musicale, istintiva, non programmatica» (Montale 1976: 565), es decir, la música como trámite que conduce a la conexión con el fondo unificado de lo inconsciente (no por nada los perfumes de Correspondances de Baudelaire cantan el éxtasis del espíritu y de los sentidos), mientras que Pavese habla de una «commozione pittorica» (Pavese 1998: 110), que intenta a su vez traducir en una poética pictórica: sus poemas como plasmación de imágenes que a su vez pueden instituir entre sí múltiples correspondencias y cuyo último significado, entrevisto, es el de formar parte, como en un cuadro, de una «totalitaria realtà fantastica» (Pavese 1998: 111). Esas correspondencias no remitirían, por tanto, en la poética de Lavorare stanca, a un referente indeterminado sino a una realidad definida y completa («totalitaria») de carácter fantástico, realidad que no por ser imaginada o inventada, carecería de concreción ni de unos límites, a los que Pavese, a mi modo de ver, alude en otros momentos de su escrito, como cuando observa que «ogni slancio di poesia /.../ è sempre un attento riferimento alle esigenze etiche, e naturalmente anche pratiche, dell'ambiente che si vive» (Pavese 1998: 108), o como cuando pone los límites de las relaciones fantásticas en la adhesión a cuanto constituye «la personale partecipazione alla realtà spiritualmente intesa» (Pavese 1998: 112), palabras donde, a mi parecer, Pavese integra una poética realista y una poética del símbolo -no del modo simbólico-, habiéndose de entender la expresión «spiritualmente intesa» como equivalente a «simbolicamente intesa».

Es aquí donde subyace, por tanto, una de las diferencias de la poética de Lavorare stanca respecto de la poética del simbolismo propio de la modernidad: frente a la inaferrabilidad última del referente del modo simbólico, la claridad, la nitidez del referente al que apuntan las imágenes de sus poemas, desprovistas del halo de evanescencia y nebulosidad de la indeterminación; de ahí, la precisión del contenido de muchas de sus poesías-relato, precisión que el mismo Pavese ve plasmada en el «pacato e chiaro racconto de I mari del Sud» o en el «nudo e quasi prosastico verso de I mari del Sud o di Deola» (cuarta composición de Lavorare stanca), y que enun- 
cia, al concluir Il mestiere di poeta, como el «chiaro principio della sobria e diretta espressione di un rapporto fantastico nettamente immaginato» (Pavese 1998: 113). De este modo, por tanto, una imagen objetiva, nítidamente imaginada, como la que constituye, por ejemplo, el ermitaño de Paesaggio, con todas sus potenciales correspondencias, puede devenir símbolo de una realidad definida y completa.

En este orden de cosas, sería interesante investigar hasta qué punto, en las poesías de Lavorare stanca, las posibles correspondencias, los juegos de las relaciones fantásticas, que se pueden establecer entre las imágenes, son germen de una poesíaracconto, o se actualizan como racconto en la propia poesía en que se encuentran. Pavese al respecto es drástico cuando reconoce más tarde, en A proposito di certe poesie ancora non scritte (1940) -donde examina a fondo Lavorare stanca con una intención prospectiva, es decir, con la mente proyectada en la búsqueda de una nueva poética- que ninguna poesia de Lavorare stanca, en realidad, tiene como argumento el contenido de una relación fantástica, es decir, el contenido de las correspondencias que se pueden establecer entre las diferentes imágenes: «Tu hai sinora evocato figure reali radicandole nel loro campo con paragoni interni, ma questo paragone non è mai stato esso stesso argomento del racconto» (Pavese 1998: 117). Según estas palabras, la «totalitaria realtà fantastica», que podría emerger de las correspondencias entre las imágenes, no habría sido actualizada en su poesía, habría quedado en pura potencialidad. Por ejemplo, si volvemos al poema Paesaggio, en efecto, las imágenes que están disociadas entre lo alto y lo bajo del poema (lo alto y lo bajo del paisaje), no se combinan ulteriormente, desplegando la potencialidad narrativa de las relaciones que podrían establecerse entre ellas, para generar de este modo un relato. A mi parecer, sin embargo, sí que se convierten, en un auténtico semillero de posibles relatos que aunque no desplegados en el poema o, en general, en Lavorare stanca, pueden germinar, sin embargo, en la imaginación del poeta y del lector. De hecho, sabemos, por el propio Pavese y por su propia obra que, tras la segunda edición de Lavorare stanca, desarrolla una gran actividad narrativa, de modo que podría decirse que sus novelle y romanzi actualizan la rica potencialidad narrativa encapsulada en las imágenes y en las relaciones fantásticas ${ }^{6}$ que ha concebido y vertido en su poesía.

\footnotetext{
${ }^{6}$ Como he indicado, no hay que olvidar que cuando Pavese escribe las palabras citadas, tiene ya in mente una poética que dialécticamente nace de la negación de la anterior. De hecho, sobre el futuro «canzoniere» que seguirá a Lavorare stanca, dice: «Questo nuevo canzoniere porterà in sé la sua luce quando sarà fatto, quando cioè dovrai negarlo» (Pavese 1998: 117)). Por otra parte, Pavese en el segundo escrito del apéndice a Lavorare stanca, A proposito di certe poesie ancora non scritte, es muy crítico respecto de la definición que ha dado de imagen en Il mestiere di poeta: «L'ambiziosa definizione del 1934, che l'immagine fosse stessa argomento del racconto, si è chiarita falsa o per lo meno prematura» (Pavese 1998:117); y un poco antes ha indicado que en poesías como Ulisse, Gente spaesata, Mania di solitudine «non si esce dalla figura umana veduta nei suoi gesti essenziali e attraverso questi raccontata», terminando por considerar el naturalismo como un punto de referencia de la poética de Lavorare stanca: «Non è un caso infine che tu abbia intravisto la possibile unità di Lavorare stanca soltanto sotto forma di avventura naturalistica». No se puede profundizar ahora en estas consideraciones, hechas seis años después de Il mestiere di poeta, cuando Pavese tiene in mente el proyecto de una nueva poética que quiere decididamente simbólica. Pero no podemos olvidar, en este aspecto, la forma en que el naturalismo está entrelazado con la poética del simbolismo, por ejemplo, en un autor como Zola. Y, por otra parte, «una figura umana veduta nei suoi gesti essenziali e attraverso questi raccontata» ¿no es una figura, una imagen objetiva que deviene símbolo y a la vez contiene los rasgos potenciales de un relato, como ocurre con la figura del ermitaño de Paesaggio?
} 
Por ello, a pesar de las afirmaciones del propio Pavese sobre la no actualización narrativa, en su poesía, de la potencialidad fantástica de sus imágenes, creo que sería interesante verificar en Lavorare stanca cómo esa potencialidad de relaciones entre las imágenes hace progresar el propio poema, generando nuevas imágenes, independientemente de que las mismas se materialicen o no en un poema-relato a sé. En este sentido, podría analizarse, por ejemplo, un poema como Donne appassionate (1998: 59), compuesto por cuatro estrofas, donde el denso juego de la sucesión de las imágenes describe y narra a la vez la escena del baño en el mar, al atardecernoche, de un grupo de jóvenes; un poema que, con palabras del propio Pavese, es un verdadero «racconto di immagini», o donde: «l' immagine [es], oscuramente, il racconto stesso» (Pavese 1998: 111). El tiempo del poema es el presente, tiempo que «hace destacar mejor el objeto. Este último [...] aparece más manifiesto y más fidedigno $[\ldots]$ más tenso porque la narración gracias a la metáfora temporal del presente, participa de la tensión del mundo comentado. [...] Es el tiempo de la cercanía de la experiencia» (Weinrich 1974: 161-162). En la primera estrofa aparece el sujeto, «le ragazze», y el marco espacio-temporal de la escena ${ }^{7}$, con imágenes (metáforas y epítetos) en que se proyecta y revela el mundo psíquico: el miedo («emergono caute» [le ragazze]) a lo indeterminado, a lo desconocido, a lo remoto-lejano: el miedo, la inquietud, también, a todo cuanto de desconocido y de inquietante «arde» (recordar la semántica del título: «donne appassionate») en lo inconsciente y que se proyecta en las imágenes externas: «ogni foglia trassale», «i giochi inquieti» [della schiuma], «il mare svanisce», «l'acqua remota». La segunda estrofa es un despliegue de la potencialidad semántica inherente a las imágenes de la primera: amplifican y concretizan el tema del miedo, de la atracción-repulsión que sobre las jóvenes ejerce el baño nocturno en el mar ${ }^{8}$. La última parte de la estrofa, sus últimos cuatro versos, sin embargo, son dialécticos respecto del contenido de la primera parte, respecto del miedo de las jóvenes; estas no se refugian en el bosque, no van tierra adentro, se quedan a la orilla confrontando al mar, confrontando el miedo: «ma piace alle scure ragazze / star sedute all'aperto, nel lenzuolo raccolto», actitud que constituye el enlace con la tercera estrofa: «Stanno tutte accosciate [...] e contemplano il mare disteso / come un prato al crepusculo» ${ }^{9}$. En las imágenes finales de esta tercera estrofa se intensifican los rasgos del miedo-repulsión: las algas se animalizan, saltan, envuelven los cuerpos, y el mar vigila con sus ojos a sus presas (vv. 20-23).

7 «Le ragazze al crepuscolo scendono in acqua, / quando il mare svanisce, disteso. Nel bosco / ogni foglia trasale, mentre emergono caute / sulla sabbia e si siedono a riva. / La schiuma / fa i suoi giochi inquieti, lungo l'acqua remota» (vv. 1-5).

${ }^{8}$ «Le ragazze han paura delle alghe sepolte / sotto le onde, che afferrano le gambe e le spalle: / quant'è nudo, del corpo. Rimontano rapide a riva / e si chiamano a nome, guardandosi intorno. / Anche le ombre sul fondo del mare, nel buio, / sono enormi e si vedono muovere incerte, / come attratte dai corpi che passano. Il bosco / è un rifugio tranquillo, nel sole calante, / più che il greto, ma piace alle scure ragazze / star sedute all'aperto, nel lenzuolo raccolto» (vv. 6-15).

9 «Stanno tutte accosciate, serrando il lenzuolo / alle gambe, e contemplano il mare disteso / come un prato al crepuscolo. / Oserebbe qualcuna / ora stendersi nuda in un prato? Dal mare / balzerebbero le alghe, che sfiorano i piedi, / a ghermire e ravvolgere il corpo tremante. / $\mathrm{Ci}$ son occhi nel mare, che traspaiono a volte» (vv. 16-22). 
Estas imágenes emergen de la proyección sobre el mar de las emociones, sensaciones, deseos y miedos desconocidos que anidan en el fondo de lo inconsciente de las jóvenes. ¿De dónde procede, en cambio, la analogía «mare-prato» de esta estrofa?: «e contemplano il mare disteso / come un prato al crepuscolo» (vv. 17-18). Así como las imágenes referidas al mar, en la estrofa precedente, surgían de la subjetividad de las jóvenes - de la «objetividad» inherente a la tercera persona, no de la subjetividad de la primera, del yo poético-, esta otra imagen puede decirse que emerge de una asociación analógica que realiza el propio yo que narra y describe. La pregunta que inmediatamente sigue a ese símil podría ser prueba de ello: «Oserebbe qualcuna / ora stendersi nuda in un prato?» (vv. 18-19) ¿Qué puede significar en una joven extenderse desnuda en un prado, a la hora del crepúsculo? ¿Qué puede implicar esa acción? El mundo del eros femenino, del sexo aún desconocido, del deseo-miedo, de la atracción-repulsión que ese mundo ejerce sobre las jóvenes, proyectado en el baño nocturno en el mar, emerge, a mi modo de ver, del fondo de lo no dicho en este poema, representado y narrado solo a través de imágenes, de esta apenas citada del «mare-prato» así como de las restantes: «Dal mare [dal mare-prato] / balzerebbero le alghe, che sfiorano i piedi, / a ghermire e ravvolgere il corpo tremante. / $\mathrm{Ci}$ son occhi nel mare, che traspaiono a volte» (vv. 19-22).

La cuarta estrofa y final constituye la condensación en un micro-relato de cuanto ha sido representado en las anteriores a través de las imágenes ${ }^{10}$. Aparece el imperfecto, tiempo del mundo narrado: «quell'ignota straniera, che nuotava di notte», «era grande e doveva esser bianca», aunque también se produce una intensa metáfora temporal a partir de los tiempos del mundo comentado: el presente («quando muta la luna», «e non torna mai più») y el pretérito perfecto («è scomparsa una notte»), cargando de intensidad y dramatismo el contenido del micro-relato, acercándolo al mundo de las jóvenes, confirmando la razón de su miedo y repulsión al mar: «è scomparsa una notte e non torna mai più»; un miedo y una repulsión que hacen presentir otras repulsiones y miedos, más horrorosos y profundos, no explicitados pero entrevistos a través de las imágenes del poema. Sí que podríamos afirmar, por tanto, que de las imágenes y de las relaciones de imágenes que se van sucediendo a lo largo de las estrofas, emerge en este poema la potencialidad de un relato, y que en su conclusión se materializa y concreta un micro-relato coherente con la potencialidad fantástica de las imágenes que han precedido.

A final de Il mestiere di poeta Pavese confiesa la dificultad que entraña el mantener firmes los principios de poética que ha defendido en su escrito. El riesgo consiste siempre en caer en dos peligros de la poética simbolista que por todos los medios él quiere evitar: el de la entrada de la subjetividad en el poema y con ello -precisamente por ello- el riesgo de la indeterminación, de la evanescencia referencial, de la «nebulosidad del contenido», propias del modo simbólico moderno. Ya hemos mencionado el pasaje en que Pavese considera que la intromisión del yo en

10 «Quell'ignota straniera, che nuotava di notte / sola e nuda, nel buio quando muta la luna, / è scomparsa una notte e non torna mai più. / Era grande e doveva esser bianca abbagliante / perché gli occhi, dal fondo del mare, giungessero a lei» (vv. 23-27). 
el poema se produce precisamente a través del juego incontrolado de los «rapporti fantastici», del establecimiento incontrolado de correspondencias entre las imágenes: «[...] alla preeminenza dell'io mi pareva di vedere accompagnarsi un più sregolato gioco di rapporti fantastici. Quando, insomma, la potenza fantastica diventa arbitrio? La mia definizione dell'immagine non mi diceva nulla in proposito», terminando por confesar que es esta la dificultad de la que todavía no ha logrado salir, constituyendo el punto crítico de toda poética.

Pavese concluye Il mestiere di poeta dándose cuenta, por tanto, de algo que Montale había planteado también en su Intervista immaginaria, cuando trata de su segundo libro, Le occasioni. Allí, Montale decía que su libro, «tentava di abbattere quella barriera fra interno ed esterno che mi pareva insussistente anche dal punto di vista gnoseologico. Tutto è interno e tutto è esterno per l'uomo d'oggi; senza che il cosiddetto mondo sia necessariamente la nostra rappresentazione» (Montale 1976: 567). Recordemos cómo precisamente en su segundo libro Montale plantea con toda intensidad la dialéctica dentro-fuera y cómo trata de resolverla y materializarla en su poesía: «Ammesso che in arte esista una bilancia tra il di fuori e il di dentro, tra l'occasione e l'opera oggetto, bisognava esprimere l'oggetto e tacere l'occasione spinta» (Montale 1976: 566-567), palabras que definen su plena adhesión a la poética del correlativo objetivo. Pavese, por su parte, descubre que tras el juego de los «rapporti fantastici» que pueden establecerse entre las imágenes, está siempre en definitiva el yo, un yo que, en principio, puede decidir desaparecer tras la representación objetiva y la tercera persona pero que se hace presente en el momento en que empiezan a emerger las imágenes y a plasmarse la red de correspondencias que se puede establecer entre ellas. Y en la entrega a ese juego indiscriminado Pavese descubre que se filtra la «opacidad subjetiva», descubre que sus imágenes, sus «rapporti fantastici» -y es muy significativo el uso de este posesivo por parte de Pavese, que de un modo inconsciente está revelando la imposible cancelación del yo de la práctica poética- «andavano sempre più complicandosi e ramificando in atmosfere rarefatte» (Pavese 1998: 113). Un poco antes había observado: «diventavo sempre più capace di sottointesi, di mezze tinte, di composizione ricca, e sempre meno convinto dell'onestà, della necessità del mio lavoro» (Pavese 1998: 113). ¿Dónde, pues, están los límites de esta práctica poética, que poco a poco se desliza hacia la indeterminación referencial tan contraria a la precisión objetiva que perseguía la poética de Lavorare stanca, los límites que, según nuestro autor, la justifican y la hacen "honesta" y "necesaria"?".

Con esta insatisfacción concluye Il mestiere di poeta, al que sigue el escrito $A$ proposito di certe poesie non ancora scritte de 1940, una reflexión cuya última parte

11 Como hemos indicado, Pavese en otros momentos de Il mestiere di poeta expresa cuáles podrían ser esos límites, cuando observa que «ogni slancio di poesia [...] è sempre un attento riferimento alle esigenze etiche, e naturalmente anche pratiche, dell'ambiente che si vive» (Pavese 1998:108); o cuando dice que el criterio de oportunidad en el juego de la fantasía consistiría en una «discreta aderenza a quel complesso logico e morale che costituisce la personale partecipazione alla realtà spiritualmente intesa» (Pavese 1998: 112), consideración, sin embargo, que no le satisface del todo pues «la debolezza della definizione risulta da quella discrezione così necessaria e così poco concludente agli effetti del giudizio sull'opera» (Pavese 1998: 112). 
contiene una declaración poética de intenciones y que es interesante poner en relación con La terra e la morte, de 1945, la última raccolta publicada en vida de Pavese, compuesta por nueve poesías. En ese escrito Pavese, por un lado, parece elegir para el futuro una poética de la alegoría, cuando dice que «in questa poesia i fatti averranno $[\ldots]$ non perché così vuole la realtà, ma perchè così decide l'intelligenza», y que sus poesías y próximo canzoniere «non saranno un'autobiografia ma un giudizio», poniendo como ejemplo a Dante: «come succede insomma nella Divina Commedia - (bisognava arrivarci)» (Pavese 1998: 118), pero, por otro lado, concluye optando por una poética que excluye a la alegoría, «avvertendo che il tuo simbolo vorrà corrispondere non all'allegoria ma all'immagine dantesca» (Pavese 1998: 118), unas palabras difíciles de interpretar pero que relacionadas con lo que luego Pavese realiza en La terra e la morte, hace que pongamos nuestra atención en la idea de imagen.

Creo que con La terra e la morte (1945) Pavese se sitúa en el espacio límite en el que puede hacerlo el yo poético, el sujeto de la escritura. Se sitúa interiormente antes de la imagen aunque para expresar lo que percibe y reconoce tenga que utilizar imágenes. Estas imágenes a su vez son inseparables de lo reconocido y percibido. Se sitúa en una instancia enunciativa que no es «sfogo» ni «scavo» subjetivos sino reducto primero de la contemplación y del reconocimiento del yo consciente, cuya única actividad, íntimamente ligada a la contemplación, es la de la palabra dirigida a nombrar el objeto contemplado. Se trata de la representación en imágenes de una experiencia arquetípica, que en sí misma es intraducible y que la imaginación proyecta en un tú femenino, imagen del aspecto desconocido de sí mismo, del fondo profundo y oscuro de donde mana la propia realidad del sujeto y, a la vez, de toda la realidad. Pavese se sitúa, pues, ante la imagen arquetípica, exponiéndose a su radiación numinosa, que puede ser tanto de luz como de oscuridad, de revelación como de silencio, tanto salvífica como destructora.

La imagen, desde esta perspectiva, ya sea en Dante o en otro poeta, por si sola considerada, es, como ha observado Jung, una manifestación inmediata de lo inconsciente colectivo, un fragmento de pura naturaleza que se impone a la percepción inmediata y en la que se proyecta ese fondo inconsciente. Requiere de una labor de integración, de asimilación de la consciencia para que pueda elevarse a la categoría de símbolo, (desde la perspectiva de la poética medieval de Dante, a la categoría de alegoría). Requiere de la confrontación con la consciencia y de un trabajo de asimilación que permita hallar en ella un sentido. La transformación de la imagen arquetípica en símbolo, es decir, en algo dotado de significado, logra canalizar en sentido constructivo y salvífico la energía liberada por la imagen arquetípica, que diríamos se muestra en estado bruto. El símbolo sería, en este sentido, «una máquina transformadora de la energía» (Jung 1995: 53), que permitiría el uso y aprovechamiento de esa energía en beneficio del sujeto. Pero esta transformación de la imagen arquetípica en símbolo no parece ocurrir, a mi modo de ver, en La terra e la morte, donde el yo se muestra inerme ante la pura imagen arquetípica, incapaz de asimilarla a través de una labor de la consciencia, quedando también, por ello, a merced de la radiación de su fuerza destructora cuando se manifiesta en su aspecto negativo y oscuro, como ocurre en esta obra. Podría decirse que en la gradación 
existente entre arquetipo -no aprehensible de modo directo-, imagen arquetípica en la que el arquetipo cristaliza y único modo en que aquél se hace perceptible a la conciencia, y símbolo, integración consciente de la imagen arquetípica en la conciencia, Pavese en su última obra poética se sitúa ante la pura imagen arquetípica, previa a la elaboración del símbolo. Si hubiera tratado de convertir sus imágenes en símbolo, como en un momento dado apunta al proponerse seguir el ejemplo de Dante, ello habría significado -el encontrar un sentido a sus imágenes- su salvación psíquica; la asimilación consciente de esas imágenes le habría ayudado a eliminar «la disociación amenazadora», «lo habría puesto a cubierto del peligroso aislamiento que siente todo aquel que se enfrenta con una parte incomprensible, irracional, de su personalidad» (Jung 1982: 439). «In habentibus symbolum facilis est transitus», dice un adagio alquimista frecuentemente citado por Jung (1982: 426). Los contenidos numinosos de las imágenes, salvíficos pero también destructores, integrados en representaciones simbólicas facilitan la transformación del yo, el paso de un estado a otro más amplio de conciencia, mientras que la disociación, la separación de esos contenidos del yo consciente, y su continuo progreso en la psique, aumenta el riesgo de la descomposición y de la destrucción de la personalidad ${ }^{12}$.

Estas imágenes en el poemetto de Pavese proceden de lo inconsciente, del fondo arquetípico, ensoñado como mar: «Terra rossa terra nera / tu vieni dal mare» (I, 12); «Sempre vieni dal mare» (VII, 1), y se proyectan en la multiplicidad de las formas y aspectos del tú de la tierra: la colina, la viña, las piedras, todos los ruidos de la naturaleza; tú, que en otro nivel de lectura, es también la mujer; las sensaciones de la infancia, son igualmente ese tú que es a la vez la oscuridad y el silencio de donde proceden. Pavese es consciente de que en esta obra se ha instalado plenamente en la poética de las correspondencias, donde todas las cosas coinciden en una tenebrosa y profunda unidad, y menciona a D'Annunzio para caracterizar al conjunto de sus nuevas poesías, "poesie diversissime da Lavorare stanca (in settenari) e quasi dannunziane» (Pavese 1998: 116). El juego de las correspondencias se va desplegando en las diferentes estrofas, con un ritmo de idas y venidas, en una ensoñación que trae a la memoria la dannunziana del paisaje en Meriggio, solo que en D'Annunzio el yo poético, identificado con el tú, es decir, con los aspectos desconocidos e inconscientes de sí mismo, se funde y confunde con las formas proyectadas desde ese fondo inconsciente en el paisaje; el yo dannunziano pierde su nombre, su identidad personal e individual para entrar a formar parte de la realidad arquetípica: «E non ho più nome. / . . / Non ho più nome / che suona in labbra umane. / Non ho più nome né sorte / tra gli uomini; ma il mio nome / è Meriggio. / In tutto io vivo / tacito come la Morte» (vv. 106-109).

12 Jung en Símbolos de transformación considera (1989) «que por lo regular se requiere una intervención ajena para suprimir esa disociación. Si yo hubiera tratado a Miss Miller [Jung en esta obra estudia el caso de una joven norteamericana a la que no trató ni conoció personalmente y que terminó desarrollando una grave esquizofrenia], habría tenido que comunicarle algo de lo que figura en este libro, para así educar su conciencia a fin de que hubiese podido captar los contenidos de lo inconsciente colectivo. Sólo con la ayuda de las «representaciones colectivas» (Lévy-Bruhl), que ya entre los primitivos poseen significación psicoterápica, cabe entender las relaciones arquetípicas de los productos de lo inconsciente. En ningún caso basta una psicología orientada de modo personalista exclusivamente» (Jung 1989: 439). 
En Pavese, en cambio, no hay identificación ni fusión con el tú. El yo se diferencia, combate con el tú, a la vez que paradójicamente lo reconoce igual a sí mismo: «Noi sempre combattemmo. /.../ Come buoni nemici / che non s'odiano più / noi abbiamo una stessa / voce /.../ e viviamo affrontati /.../ Combatteremo ancora, / combatteremo sempre» (VII). Eterna confrontación, por tanto, con ese fondo oscuro que se proyecta en el tú, del que el yo se distancia porque ese fondo «no sabe», es inconsciente: no sabe del sufrimiento de los hombres que han muerto en la resistencia $(\mathrm{V})$; no sabe del dolor de la condición humana, aunque paradójicamente él mismo -o ella misma, pues es el arquetipo del ánima el que se ha constelado en Pavese- sea dolor y se manifieste como dolor; y no lo sabe porque no lo siente y no lo siente porque es inconsciente: «Quando sembri destarti / sei soltanto dolore, / l'hai negli occhi e nel sangue / ma tu non lo senti. Vivi / come vive una pietra, / come la terra dura» (IX, 1-6).

Por ello, la poética que también se debate en el fondo de este poema es la de la epifanía, no como revelación realizada sino como expectativa o posibilidad de realización: es decir, como expectativa de que se dé la palabra-revelación frente al silencio, como posibilidad de una poesía que sea expresión de ese fondo último de la realidad en oposición a una poesía incapaz de revelación alguna. También en este aspecto esta poesía se relaciona con D'Annunzio, con la consciencia que este poeta tenía del silencio de las cosas, del secreto inaccesible e inexpresable que encierra el fondo último de la realidad aunque la voluntad de poder-decir alcyonica se hiciera la ilusión alguna vez de ser capaz de desvelarlo y de expresarlo: «e ti dirò per qual segreto / le colline su i limpidi orizzonti / $\mathrm{s}$ ' incùrvino come labbra che un divieto / chiuda, e perché la volontà di dire / le faccia belle / oltre ogni uman desire» (La sera fiesolana: vv. 39-43); mientras que otras veces, como hemos visto en la conclusión de Meriggio, el poeta cede al silencio a través de la disolución del yo poético.

El tema de la palabra frente al silencio recorre la composición de Pavese de forma que toda ella se puede interpretar, desde un nivel metapóetico, como su última manifestación de poética, inscrita en la modalidad de la poética de las correspondencias y de la voluntad epifánica; una poética que, de un modo inquietante, propone, a mi modo de ver, lo que podría llamarse una poética del silencio. Se puede escribir una poesía desde el silencio: sería la de los místicos, la de aquellos que han muerto al yo, donde la palabra ya no surge desde esa instancia sino desde otra no identificada con la subjetividad individual. Y en cierto sentido, quizá, podría decirse que este poema de Pavese está escrito desde una noche oscura del alma, no en el sentido religioso convencional, sino en el de quien ha perdido el contacto con el aspecto positivo, animante y vivificador, del arquetipo del ánima, puente hacia el símismo, y se debate en el más profundo abandono. En La terra e la morte el yo, sin embargo, no desaparece, como ocurre en la experiencia mística; se limita a contemplar y a reconocer la carencia de palabras, el silencio, tanto del fondo desconocido que se proyecta en formas e imágenes, como del propio yo que no encuentra palabras para poder nombrarlo: «Tu sei come una terra / che nessuno ha mai detto. / Tu non attendi nulla / se non la parola / che sgorgherà dal fondo» (II, 1-4); «Tu non dici parole. /.../ Sei un chiuso silenzio / che non cede, sei, / labbra e occhi bui. /.../Sei la vigna. / È una terra che attende / e non dice parola» (III); «Nel cuore / hai silen- 
zio, hai parole / inghiottite. Sei buia. / Per te l'alba è silenzio» (IV); «La parola non c'è che ti può possedere / o fermare. / . . / e non dici parole / e nessuno ti parla» (VI). En vez de palabras, ese fondo tiene voz, algo que en oposición a aquellas, carece para Pavese de consciencia y de voluntad de comunicación; la voz no se diferencia del fondo de donde procede: «E sei come le voci della terra» (IV); «Sei la voce roca della campagna, il grido della quaglia nascosta» (VI); «Sempre vieni dal mare / e ne hai la voce roca» (VII).

Solo hay un momento en la primera estrofa en que ese tú aparece asociado a la palabra: «Terra rossa terra nera, tu vieni dal mare, dal verde riarso, dove sono parole antiche /.../ non sai quanto porti di mare parole /; / . . tu dura e dolcissima parola, antica per sangue /.../giovane, come un frutto / che è ricordo» (I). La palabra de la que habla aquí el yo poético es antigua, y procede del mar como del mar procede la tierra; esta última, cuando sale del mar, lleva consigo la palabra, una palabra cargada de contenidos del fondo oscuro de donde procede; pero eso ocurrió al principio, cuando la palabra era antigua y los primeros hombres fueron capaces de nombrarla con sus símbolos y mitos y cuando, a su vez, ella habló a aquellos hombres. Al hombre moderno solo le queda el recuerdo de aquella palabra.

\section{Bibliografía}

BERARDINELli, Alfonso (2008): Poesia non poesia. Torino, Einaudi.

CURI, Franco (1999): La poesia italiana nel Novecento. Roma-Bari, Laterza.

JUNG, Carl. G. (1982): Símbolos de transformación. Barcelona, Paidós.

JuNG, Carl G. (1995): Energética psíquica y esencia del sueño. Barcelona, Paidós.

LUZI, Mario (1976): L'idea simbolista. Milano, Garzanti.

MAZZONI, Guido (2005): Sulla poesia moderna. Bologna, Il Mulino.

MonTALE, Eugenio (1976): Sulla poesia. Milano, Mondadori.

Montale, Eugenio (1995): Tutte le poesie. Milano, Mondadori.

PAVESE, Cesare (1998): Le poesie, a cura di Mariarosa Masoero. Torino, Einaudi.

WeINRICH, Harald (1974): Estructura y función de los tiempos en el lenguaje. Madrid, Gredos. 